\title{
New V-shaped 2,4-di(hetero)arylpyrimidine push-pull systems: Synthesis, solvatochromism and sensitivity towards nitroaromatic compounds
}

\author{
Egor V. Verbitskiy ${ }^{\mathrm{a}, \mathrm{b}, *}$, Ekaterina M. Dinastiya ${ }^{\mathrm{a}}$, Anna A. Baranova ${ }^{\mathrm{b}}$, Konstantin O. Khokhlov ${ }^{\mathrm{b}}$ \\ Roman D. Chuvashov ${ }^{\mathrm{b}}$, Yuliya A. Yakovleva ${ }^{\mathrm{b}}$, Nadezhda I. Makarova ${ }^{\mathrm{c}}$, Elena V. Vetrova ${ }^{\mathrm{c}}$, \\ Anatoly V. Metelitsa ${ }^{c}$, Pavel A. Slepukhin ${ }^{\mathrm{a}, \mathrm{b}}$, Gennady L. Rusinov ${ }^{\mathrm{a}, \mathrm{b}}$, Oleg N. Chupakhin ${ }^{\mathrm{a}, \mathrm{b}}$, \\ Valery N. Charushin ${ }^{\mathrm{a}, \mathrm{b}}$ \\ a I. Postovsky Institute of Organic Synthesis, Ural Branch of the Russian Academy of Sciences, S. Kovalevskaya Str., 22, Ekaterinburg, 620990, Russia \\ ${ }^{\mathrm{b}}$ Ural Federal University, Mira St. 19, Ekaterinburg, 620002, Russia \\ ${ }^{\mathrm{c}}$ Institute of Physical and Organic Chemistry, Southern Federal University, Stachki Av., 194/2, Rostov on Don, 344090, Russia
}

\section{A R T I C L E I N F O}

\section{Keywords:}

Pyrimidine

Carbazole

Triphenylamine

Pyrene

Solvatochromism

Fluorescence quenching

\begin{abstract}
A B S T R A C T
Novel D- $\pi-\mathrm{A}-\pi-\mathrm{D}$ type pyrimidine-based dyes, possessing (hetero)aryl electron-donating groups in 2,4-positions were synthesized, and their photophysical properties were investigated by using absorption and emission spectral analyses. All dyes proved to exhibit a strong emission solvatochromism with quantum yields up to 0.96 , depending on their molecular structure and solvent polarity. The compounds have been established to undergo a reversible protonation, directed at nitrogen atoms of the pyrimidine ring, and these phenomena are associated with dramatic color changes. In addition, fluorophores 5a-d show a high sensitive response for nitroaromatic traces in solutions or real-time detection of their vapors in air. These findings indicate that the compounds obtained can be regarded as excellent fluorophores for fluorescent material applications.
\end{abstract}

\section{Introduction}

During the last two decades, the family of fluorescent pyrimidine sensors of the D- $\pi$-A type (donor- $\pi$-acceptor), has demonstrated a growing interest due to their high sensitivity, selectivity and easy measurements [1]. Another fascinating advantage of such materials is that their electro-optical properties can be tuned effectively by judicious choice of electron-donating and electron-withdrawing substituents [1]. Particularly, pyrimidine fluorophores have been used as metal cation [2-4], polarity [5-9] and $\mathrm{pH}$ [9-12] sensors, and those structures with a larger absorption and emission wavelengths can also be applied in biological and medical studies [13,14]. Recently, the straightforward synthesis of the series of 4-(hetero)aryl (I), 4,5-di (hetero)aryl (II) and 4,5,6-tri(hetero)aryl (III) substituted pyrimidines by using the methodology of nucleophilic aromatic substitution (the $\mathrm{S}_{\mathrm{N}}{ }^{\mathrm{H}}$ protocol) [15] has been described, and these structures can be applied for effective detection of various nitroaromatic explosives (see Fig. 1) [16-21].

As a further extension of our research studies on the design of novel fluorophores for chemosensors, in this communication we wish to describe the synthesis of a new series of D- $\pi-A-\pi-D$ pyrimidine-based compounds 5a-d obtained through incorporation of appropriate electron-donative substituents into the pyrimidine ring via a 2,5-thienyl linkage, and systematic investigation of their photophysical properties, solvatochromism, structure-property relationships and applications, as fluorescent sensors for nitroaromatic explosives.

\section{Experimental section}

\subsection{General information}

All reagents and solvents were obtained from commercial sources and dried by using standard procedures before use. Nitroaromatic explosives, including 2,4-dinitroanisole (DNAN), picric acid (PA), styphnic acid (SA), 1,3,5-triethoxy-2,4,6-trinitrobenzene (TETNB), 2,4dinitrotoluene (DNT), 2,4,6-trinitrotoluene (TNT), 2,4,6-triamino1,3,5-trinitrobenzene (TATB) were of analytical grade and used directly without further purification. (Caution: All nitro-containing compounds used in the present study are high explosives and should be handled only in small analytical quantities). The solvents (1,4-dioxane and $\mathrm{H}_{2} \mathrm{O}$ ) for the microwave-assisted Suzuki cross-coupling reaction were deoxygenated by bubbling argon for $1 \mathrm{~h}$.

\footnotetext{
* Corresponding author. I. Postovsky Institute of Organic Synthesis, Ural Branch of the Russian Academy of Sciences, S. Kovalevskaya Str., 22, Ekaterinburg, 620990, Russia

E-mail address: verbitsky@ios.uran.ru (E.V. Verbitskiy).
} 

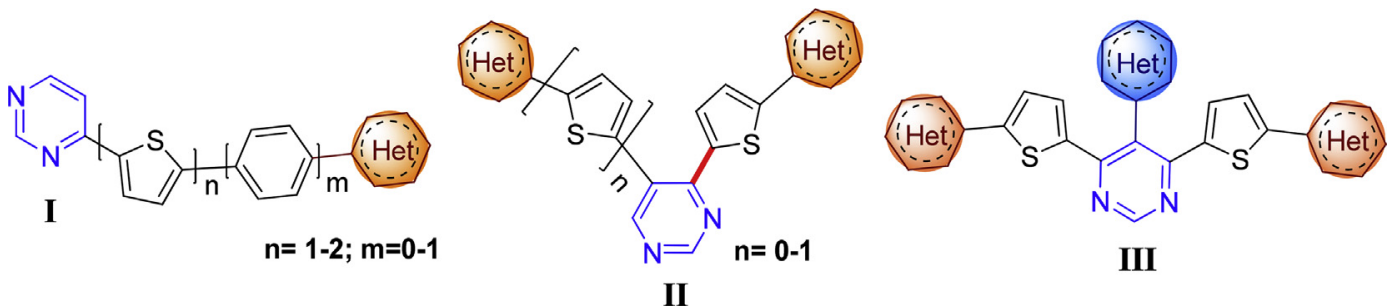

Fig. 1. Structures of push-pull pyrimidine-based fluorophores I-III.

${ }^{1} \mathrm{H}$ and ${ }^{13} \mathrm{C}$ NMR spectra were recorded on an AVANCE-500 instrument using Me4Si as an internal standard. Elemental analysis was carried on a Eurovector EA 3000 automated analyzer. High resolution mass spectrometry was performed using a Bruker maXis Impact HD spectrometer. Melting points were determined on Boetius combined heating stages and were not corrected.

Flash-column chromatography was carried out using Alfa Aesar silica gel $0.040-0.063 \mathrm{~mm}$ (230e400 mesh), eluting with ethyl acetatehexane. The progress of reactions and the purity of compounds were checked by TLC on Sorbfil plates (Russia), in which the spots were visualized with UV light ( $\lambda 254$ or $365 \mathrm{~nm}$ ).

The XRD analysis of the single crystal of 5 a was carried out using an "Xcalibur 3" diffractometer on standard procedure (MoK-irradiation, graphite monochromator, $\omega$-scans with $1^{\circ}$ step, $T=295(2) \mathrm{K}$ ). The empirical absorption correction was applied. Using Olex2, the structure was solved with the ShelXS structure solution program using Direct Methods and refined with the ShelXL refinement package using Least Squares minimization in anisotropic approximation for non-hydrogen atoms. The $\mathrm{H}$-atoms were refined in isotropic approximation in the "rider" model. Deposition number CCDC 1846582 for 5a contains the supplementary crystallographic data for this paper. These data can be obtained free of charge from the Cambridge Crystallographic Data Center via www.ccdc.cam.ac.uk/data_request/cif.

Microwave experiments were carried out in a Discover unimodal microwave system (CEM, USA) with a working frequency of $2.45 \mathrm{GHz}$ and the power of microwave radiation ranged from 0 to $300 \mathrm{~W}$. The reactions were carried out in a $10 \mathrm{~mL}$ reaction tube with the hermetic Teflon cork. The temperature of the reaction was monitored using an inserted IR sensor by the external surface of the reaction vessel.

UV/vis spectra were recorded for a $2 \times 10^{-5} \mathrm{M}$ solutions with Varian Cary 100 spectrophotometer. Photoluminescent spectra were recorded for a $(1.0-3.0) \times 10^{-6} \mathrm{M}$ solutions on a Varian Cary Eclipse fluorescence spectrophotometer. UV/vis and fluorescence spectra were recorded using standard $1 \mathrm{~cm}$ quartz cells at room temperature. The $\Phi_{\mathrm{F}}$ values were calculated using a well known procedure with quinine sulfate in $0.1 \mathrm{M} \mathrm{H}_{2} \mathrm{SO}_{4}$ [22]. Stokes shifts were calculated considering the lowest energetic absorption band.

The fluorescence quenching studies were carried out on a Hitachi F7000 fluorescence spectrophotometer at room temperature in acetonitrile. For each analyte, the typical test procedure was as follows: $2.5 \mathrm{~mL}$ of acetonitrile solution of one of the fluorophores $\left(5.0 \times 10^{-7} \mathrm{~mol} / \mathrm{L}\right)$ was drawn and placed in a quartz cell of the standard size. Without analyte the fluorescence spectrum of pure fluorophore was first recorded. Subsequently, different amounts of analyte were added respectively in the cell. Each time after full mixing the analyte with fluophore, the fluorescence spectrum was registered. The plots of $I_{0} / I$ values of the quenching systems as functions of quencher concentrations ([Q]) were well described by the Stern-Volmer equation, $I_{O} /$ $I=1+K_{\mathrm{sv}}[\mathrm{Q}]$, where $I_{O}$ and $I$ are fluorescence intensities without and in the presence of analyte. The detection limits were calculated by use literature procedure (see details in Supporting Information). To investigate detection of nitroaromatic explosives in vapor phase the original device « Zaslon-M» (see Fig. S1 in Supporting Information) has been used.
This device was produced by company «EnergoSpetsKomplektServis» (Moscow region, Mytischi, Russia). The instrument is based on registration of excited steady-state luminescence quenching. Sensors for this device were obtained by application of a dye solution on the cellulose matrix. Reduction of the luminescence intensity of the sensor takes place due to an interaction with explosive vapors contained in the air. The decrease rate of the luminescence intensity indicates at the concentration of vapors. To study luminescent properties of the sensor element, its luminescence spectra excited by photons with energies in the range $280-425 \mathrm{~nm}$ were measured. The excitation photoluminescence spectra for luminescence bands of the sensor element were also measured. Excitation source was light emitting diode $(375 \mathrm{~nm})$, and luminescent signal receiver was a photodiode (430-650 $\mathrm{nm}$ ) in the device. The device was operating under control of the program algorithm, which provides multiple operating modes (configuration, calibration, measurement etc.). The advantages of this device are autonomic power, a low weight and small sizes, as well as simplicity of operations for measurements. The calibration of the device «Zaslon-M» was carried out by using the internal software. The fluorescence measurements (excited at $375 \mathrm{~nm}$ ) for nitroaromatic vapors were performed with the device « Zaslon- $\mathrm{M}$ » connected with a computer.

The sensor for detection of NACs in vapor phase has been designed as cartridge [16]. The cartridge has two parts which are connected at the contour of the framework. In previous investigation, it has been shown that non-woven spunlace fabric $(70 \%$ viscose, $30 \%$ polyester, Industrial Spunlace purchased from Afalina Co., Ltd., Russia) is the best porous substrate for fabrication of sensors [19]. The parts of cartridge made from Plexiglas were connected to each other along the contour by means of acrylonitrile glue. A piece of spunlace $(50 \mathrm{~mm}$ in diameter) was immersed in the fluorophore solution with a concentration $1.0 \times 10^{-3} \mathrm{M}$ for $5 \mathrm{~min}$. Then, spunlace with immobilized fluorophore $5 \mathbf{a}(\mathbf{5 b}, \mathbf{5} \mathbf{c}$ or $\mathbf{5 d})$ was removed from the solution and dried at $70-80^{\circ} \mathrm{C}$ for $30 \mathrm{~min}$. To demonstrate its application as a fluorescence sensor for NAC detection, the obtained spunlace was placed in cartridge.

To detect vapors of nitroaromatic compounds, such as TNT (400 mg), 2,4-DNT (1.0 g) and nitrobenzene (1 mL) in open glass tubes ( $150 \mathrm{~mm}$ in diameter), they were placed in a hermetic glove-box $(0.8 \mathrm{~m} \times 0.6 \mathrm{~m} \times 0.4 \mathrm{~m})$. Explosive was kept in this box during $48 \mathrm{~h}$ at room temperature until saturated vapor was formed. Similar protocol was used for interferents $(15 \mathrm{~mL})$, such as ammonia, ethanol, ethylene glycol, acetone, acetic acid and toluene.

\subsection{2,4-Di(thiophen-2-yl)pyrimidine (2)}

A mixture of 2,4-dichloropyrimidine (1) (500 mg, $3.36 \mathrm{mmol}$ ), 2thienylboronic acid $(1.29 \mathrm{~g}, 10.07 \mathrm{mmol}), \mathrm{Pd}\left(\mathrm{PPh}_{3}\right)_{4}(388 \mathrm{mg}, 10 \mathrm{~mol}$ $\%)$ and $\mathrm{K}_{3} \mathrm{PO}_{3}(3.56 \mathrm{~g}, 16.78 \mathrm{mmol})$ was dissolved in 1,4-dioxane $(50 \mathrm{~mL})$. The reaction mixture was degassed and refluxed for $10 \mathrm{~h}$ under an argon atmosphere. The solvent was removed under reduced pressure, and the residue was extracted with EtOAc. The organic layer was washed with water and then saturated sodium chloride solution, dried over anhydrous $\mathrm{Na}_{2} \mathrm{SO}_{4}$, and then evaporated in vacuum to dryness. The residue was purified by silica gel column chromatography with ethyl acetate/hexane $(1: 2, \mathrm{v} / \mathrm{v})$ as an eluent to give the target compound 2. Yield $820 \mathrm{mg}$ (87\%), beige powder, mp $79-81^{\circ} \mathrm{C} .{ }^{1} \mathrm{H}$ NMR 
$\left(500 \mathrm{MHz}, \mathrm{CDCl}_{3}\right) 8.64$ (d, $\left.J=5.3 \mathrm{~Hz}, 1 \mathrm{H}\right), 8.08$ (dd, $J=3.7,1.2 \mathrm{~Hz}$, $1 \mathrm{H}$ ), 7.80 (dd, $J=3.7,1.1 \mathrm{~Hz}, 1 \mathrm{H}$ ), 7.54 (dd, $J=5.0,1.0 \mathrm{~Hz}, 1 \mathrm{H}$ ), 7.49 (dd, $J=5.0,1.2 \mathrm{~Hz}, 1 \mathrm{H}), 7.34$ (d, $J=5.3 \mathrm{~Hz}, 1 \mathrm{H}), 7.19-7.16(\mathrm{~m}, 2 \mathrm{H})$; ${ }^{13} \mathrm{C}$ NMR $\left(126 \mathrm{MHz}, \mathrm{CDCl}_{3}\right) \delta 161.4,159.0,157.5,143.2,142.3,130.3$, 129.9, 129.1, 128.3, 128.2, 127.6, 112.3. Calcd. for $\mathrm{C}_{12} \mathrm{H}_{8} \mathrm{~N}_{2} \mathrm{~S}_{2}$ (244.33): C 58.99, H 3.30, N 11.47. Found C 59.10, H 3.47, N 11.38.

\subsection{2,4-Bis(5-bromothiophen-2-yl)pyrimidine (3)}

A solution of $N$-bromosuccinimide $(1.424 \mathrm{~g}, 8.0 \mathrm{mmol})$ in DMF $(5 \mathrm{~mL})$ was added portionwise to a solution of 2,4-di(thiophen-2-yl) pyrimidine (2) ( $489 \mathrm{mg}, 2.0 \mathrm{mmol})$ in DMF $(10 \mathrm{~mL})$. Then the mixture was stirred for $24 \mathrm{~h}$ at room temperature. The reaction mixture was diluted with $\mathrm{H}_{2} \mathrm{O}$ and the precipitate formed was filtered off, washed with $\mathrm{H}_{2} \mathrm{O}$, and air-dried. The residue was purified by flash column chromatography (hexane/ethyl acetate, 1:2). The product 3 was isolated as a white powder $(756 \mathrm{mg}, 94 \%), \mathrm{mp} 148-149{ }^{\circ} \mathrm{C} .{ }^{1} \mathrm{H}$ NMR $\left(500 \mathrm{MHz}, \mathrm{CDCl}_{3}\right) \delta 8.61$ (d, $\left.J=5.4 \mathrm{~Hz}, 1 \mathrm{H}\right), 7.77(\mathrm{~d}, J=4.0 \mathrm{~Hz}, 1 \mathrm{H})$, 7.50 (d, $J=4.0 \mathrm{~Hz}, 1 \mathrm{H}), 7.26$ (d, $J=5.4 \mathrm{~Hz}, 1 \mathrm{H}), 7.14$ (d, $J=4.0 \mathrm{~Hz}$, $1 \mathrm{H}), 7.13(\mathrm{~d}, J=4.0 \mathrm{~Hz}, 1 \mathrm{H}) ;{ }^{13} \mathrm{C}$ NMR $\left(126 \mathrm{MHz}, \mathrm{CDCl}_{3}\right) \delta 160.5$, 158.1, 157.7, 144.2, 143.5, 131.3, 131.3, 129.2, 127.7, 118.7, 117.7, 111.7. Calcd. for $\mathrm{C}_{12} \mathrm{H}_{6} \mathrm{Br}_{2} \mathrm{~N}_{2} \mathrm{~S}_{2}$ (402.12): C 35.84, H 1.50, N 6.97. Found C 36.01, H 1.48, N 6.89.

\subsection{General procedure for the synthesis of 2,4-bis[5-(heteroaryl)-thiophen- 2-yl] pyrimidines (5a-d)}

A solution of $\mathrm{K}_{2} \mathrm{CO}_{3}(138 \mathrm{mg}, 1.0 \mathrm{mmol})$ in $\mathrm{H}_{2} \mathrm{O}(2 \mathrm{~mL})$ was added to a mixture of 2,4-bis(5-bromothiophen-2-yl)pyrimidine (3) $(80 \mathrm{mg}$, $0.2 \mathrm{mmol}$ ) and pinacol ester 4-(diphenylamino)phenylboronic (4a) acid [pinacol ester 9-ethyl-9H-carbazole-3-boronic (4b) acid, pinacol ester 9H-carbazole-9-(4-phenyl)boronic acid (4c) or pyrene-1-boronic acid (4d)] $(0.5 \mathrm{mmol})$ and $\mathrm{Pd}\left(\mathrm{PPh}_{3}\right)_{4}(23 \mathrm{mg}, 10 \mathrm{~mol} \%)$ in 1,4-dioxane $(4 \mathrm{~mL})$. The resulting mixture was irradiated in a microwave apparatus at $165^{\circ} \mathrm{C}(250 \mathrm{~W})$ for $25 \mathrm{~min}$. After that, solvent was distilled off in vacuo, and the residue was purified by flash column chromatography (hexane/ethyl acetate, 1:2) to afford the desired cross-coupling products $(5 a, 5 b, 5 c$ or $5 d)$.

\subsection{4,4'-[5,5'-(Pyrimidine-2,4-diyl)bis(thiophene-5,2-diyl)]bis( $N, N$ - diphenylaniline) (5a)}

Yield $108 \mathrm{mg}$ (74\%), yellow powder, $\mathrm{mp} 113-115^{\circ} \mathrm{C} .{ }^{1} \mathrm{H} \quad \mathrm{NMR}$ $\left(500 \mathrm{MHz}, \mathrm{CDCl}_{3}\right) \delta 8.60$ (d, $\left.J=5.4 \mathrm{~Hz}, 1 \mathrm{H}\right), 8.02$ (d, $\left.J=3.9 \mathrm{~Hz}, 1 \mathrm{H}\right), 7.75$ (d, $J=3.9 \mathrm{~Hz}, 1 \mathrm{H}), 7.59-7.54(\mathrm{~m}, 4 \mathrm{H}), 7.30-7.26(\mathrm{~m}, 11 \mathrm{H}), 7.15-7.13(\mathrm{~m}$, 8H), 7.10-7.03 (m, 8H); $\left.{ }^{13} \mathrm{C} \mathrm{NMR} \mathrm{(126} \mathrm{MHz,} \mathrm{CDCl}_{3}\right) \delta 161.3,158.9,157.2$, 149.2, 148.6, 148.2, 147.8, 147.4, 147.3, 141.2, 140.15, 130.16, 129.38, 129.35, 128.73, 128.04, 127.50, 126.84, 126.71, 124.81, 124.70, 123.4, 123.32, 123.28, 123.26, 123.23, 123.1, 111.5. HRMS (ESI): $\mathrm{m} / \mathrm{z}$ calcd for $\mathrm{C}_{48} \mathrm{H}_{35} \mathrm{~N}_{4} \mathrm{~S}_{2}: 731.2298[\mathrm{M}+\mathrm{H}]^{+}$; found: 731.2287.

\subsection{3,3'-[5,5'-(Pyrimidine-2,4-diyl)bis(thiophene-5,2-diyl)]bis(9-ethyl- 9H-carbazole) (5b)}

Yield $79 \mathrm{mg}$ (63\%), yellow powder, mp $231-233^{\circ} \mathrm{C} .{ }^{1} \mathrm{H}$ NMR $\left(500 \mathrm{MHz}, \mathrm{CDCl}_{3}\right) \delta 8.62(\mathrm{~d}, J=5.3 \mathrm{~Hz}, 1 \mathrm{H}), 8.45$ (dd, $J=7.0,1.4 \mathrm{~Hz}$, $2 \mathrm{H}), 8.18$ (dd, $J=11.1,7.7 \mathrm{~Hz}, 2 \mathrm{H}), 8.12(\mathrm{~d}, J=3.5 \mathrm{~Hz}, 1 \mathrm{H}), 7.84$ (ddd, $J=8.1,6.3,1.6 \mathrm{~Hz}, 2 \mathrm{H}), 7.80$ (d, $J=3.9 \mathrm{~Hz}, 1 \mathrm{H}$ ), 7.53-7.48 (m, $2 \mathrm{H}), 7.45-7.40(\mathrm{~m}, 6 \mathrm{H}), 7.32-7.27(\mathrm{~m}, 3 \mathrm{H}), 4.38(\mathrm{q}, J=7.2 \mathrm{~Hz}, 4 \mathrm{H})$, 1.47 (t, $J=7.2 \mathrm{~Hz}, 3 \mathrm{H}), 1.46(\mathrm{t}, J=7.2 \mathrm{~Hz}, 3 \mathrm{H}) ;{ }^{13} \mathrm{C}$ NMR $(126 \mathrm{MHz}$, $\left.\mathrm{CDCl}_{3}\right) \delta 161.3,159.2,156.8,151.1,150.4,140.51,140.49,140.1$, $139.9,139.8,130.4,129.7,129.0,126.2,126.1,125.5,125.1,124.23$, $124.20,123.51,123.47,123.2,123.1,123.0,122.9,120.71,120.68$, 119.3, 119.2, 118.2, 118.1, 111.4, 108.9, 108.81, 108.76, 108.7, 37.72, 37.70, 13.83 (one $\mathrm{CH}_{3}$-group is not observed). HRMS (ESI): $\mathrm{m} / \mathrm{z}$ calcd for $\mathrm{C}_{40} \mathrm{H}_{31} \mathrm{~N}_{4} \mathrm{~S}_{2}$ : $631.1985[\mathrm{M}+\mathrm{H}]^{+}$; found: 631.1978.

\subsection{9,9'-\{[5,5'-(Pyrimidine-2,4-diyl)bis(thiophene-5,2-diyl)]bis(4,1- phenylene)\}bis(9H-carbazole) (5c)}

Yield $71 \mathrm{mg}$ (49\%), yellow powder, mp $280-282^{\circ} \mathrm{C} .{ }^{1} \mathrm{H}$ NMR $\left(500 \mathrm{MHz}, \mathrm{CDCl}_{3}\right) \delta 8.71(\mathrm{~d}, J=5.3 \mathrm{~Hz}, 1 \mathrm{H}), 8.16(\mathrm{~d}, J=6.2 \mathrm{~Hz}, 4 \mathrm{H})$, 8.14 (d, $J=3.9 \mathrm{~Hz}, 1 \mathrm{H}), 7.96$ (d, $J=7.2 \mathrm{~Hz}, 4 \mathrm{H}), 7.86$ (d, $J=3.8 \mathrm{~Hz}$, $1 \mathrm{H}), 7.65$ (dd, $J=10.6,8.4 \mathrm{~Hz}, 4 \mathrm{H}), 7.51-7.48(\mathrm{~m}, 6 \mathrm{H}), 7.43$ (dd, $J=11.6,5.5 \mathrm{~Hz}, 5 \mathrm{H}), 7.33-7.30(\mathrm{~m}, 4 \mathrm{H}) ;{ }^{13} \mathrm{C} \mathrm{NMR}\left(126 \mathrm{MHz}, \mathrm{CDCl}_{3}\right) \delta$ $161.3,158.8,157.5,148.2,147.6,142.6,141.7,140.7,140.6,137.8$, $137.5,133.3,132.8,130.3,128.8,127.51,127.47,127.4,127.3,126.1$, 126.0, 124.8, 124.7, 123.6, 123.5, 120.40, 120.36, 120.2, 120.1, 112.0, 109.81, 109.76. HRMS (ESI): $\mathrm{m} / z$ calcd for $\mathrm{C}_{48} \mathrm{H}_{31} \mathrm{~N}_{4} \mathrm{~S}_{2}: 727.1985$ [M $+\mathrm{H}]^{+}$; found: 727.1986 .

\subsection{2,4-Bis[5-(pyren-1-yl)thiophen-2-yl]pyrimidine (5d)}

Yield $54 \mathrm{mg}$ (42\%), yellow powder, mp $298-300^{\circ} \mathrm{C} .{ }^{1} \mathrm{H}$ NMR $\left(500 \mathrm{MHz}, \mathrm{DMF}-d_{7}\right) \delta 8.96(\mathrm{~d}, J=5.3 \mathrm{~Hz}, 1 \mathrm{H}), 8.65$ (dd, $J=9.3$, $4.1 \mathrm{~Hz}, 2 \mathrm{H}), 8.49-8.28(\mathrm{~m}, 16 \mathrm{H}), 8.17(\mathrm{td}, J=7.6,5.9 \mathrm{~Hz}, 2 \mathrm{H}), 8.07$ (d, $J=5.3 \mathrm{~Hz}, 1 \mathrm{H}), 7.74$ (d, $J=3.9 \mathrm{~Hz}, 1 \mathrm{H}), 7.69$ (d, $J=3.8 \mathrm{~Hz}, 1 \mathrm{H})$; The ${ }^{13} \mathrm{C}$ NMR spectra of $\mathbf{5 d}$ could not be obtained due to a poor solubility of this compound in deuterated solvents. HRMS (ESI): $\mathrm{m} / \mathrm{z}$ calcd for $\mathrm{C}_{44} \mathrm{H}_{24} \mathrm{~N}_{2} \mathrm{~S}_{2}: 645.1454[\mathrm{M}+\mathrm{H}]^{+}$; found: 645.1455.

\section{Results and discussion}

\subsection{Synthesis}

To the best of our knowledge, there have only two reports, describing the synthesis of 2,4-di(thiophen-2-yl)pyrimidine (2), by exploiting the Ni-catalyzed Kumada cross-coupling [22] or the Stille cross-coupling reaction in the presence of copper (I) 3-methylsalicylate, as cofactor [23], thus affording 2 in $85 \%$ and $74 \%$ yields, respectively. For the first time, 2,4-di(thiophen-2-yl)pyrimidine (2) was prepared as a starting material by using the Suzuki cross-coupling reaction of 2,4dichloropyrimidine (1) with 2 -thienylboronic acid in $87 \%$ yield. The target compounds 5a-d were synthesized by bromination of compound $\mathbf{2}$ into 3 , followed by interaction of $\mathbf{3}$ with the corresponding pinacol esters of 4-(diphenylamino)phenylboronic (4a), 9-ethyl-9H-carbazole3-boronic (4b), 9H-carbazole-9-(4-phenyl)boronic acids (4c) or pyrene1-boronic acid (4d) under microwave irradiation in 1,4-dioxane $/ \mathrm{H}_{2} \mathrm{O}$, proceeding in the presence of $\mathrm{K}_{2} \mathrm{CO}_{3}$ and $\mathrm{Pd}\left(\mathrm{PPh}_{3}\right)_{4}$ as catalyst. These reactions proved to afford the corresponding D- $\pi-A-\pi-D$ dyes 5 a-d in $42-74 \%$ yields within the reaction times, not exceeding $25 \mathrm{~min}$ (Scheme 1). The structure of $\mathbf{5 a}$ was established unequivocally by X-ray diffraction analysis (Fig. 2; see details in Supporting Information).

\subsection{UV-Vis and fluorescence spectroscopy}

Photophysical properties of the prepared V-shaped D- $\pi-A-\pi-D$ type 2,4-di(hetero)aryl pyrimidines $\mathbf{5 a - d}$ were investigated at room temperature by using UV/vis and photoluminescence (PL) spectroscopy in five aprotic solvents with different Dimroth-Reichardt polarity parameters $\left(E_{\mathrm{T}}(30)\right.$ ), notably toluene (33.9), tetrahydrofuran (37.4), dichloromethane (40.7), acetone (42.2) and dimethyl sulfoxide (45.1) [25]. The solvatochromic spectral data of 5a-d are summarized in Table 1 (Supplementary Material, Figs. S2-S9). The aim of this study was to explore the effects of solvent polarity on photophysical properties of the fluorophores, and to correlate these effects with their structures.

The pyrimidine dyes 5a-d demonstrate absorption maxima at around $367-408 \mathrm{~nm}\left(\varepsilon=50400-68500 \mathrm{M}^{-1} \cdot \mathrm{cm}^{-1}\right)$, which can be attributed to intramolecular charge-transfer (ICT) excitation from the electron-donating moiety (triphenylamine (a), 9-ethyl-9H-carbazole (b), $9 \mathrm{H}$-carbazole (c), pyrene (d)) to the pyrimidine ring (acceptor) (Table 1). The second and third absorption maxima proved to appear at $289-318 \mathrm{~nm}\left(\varepsilon=28300-47700 \mathrm{M}^{-1} \cdot \mathrm{cm}^{-1}\right)$ and $278 \mathrm{~nm}(\varepsilon=38800$ - 


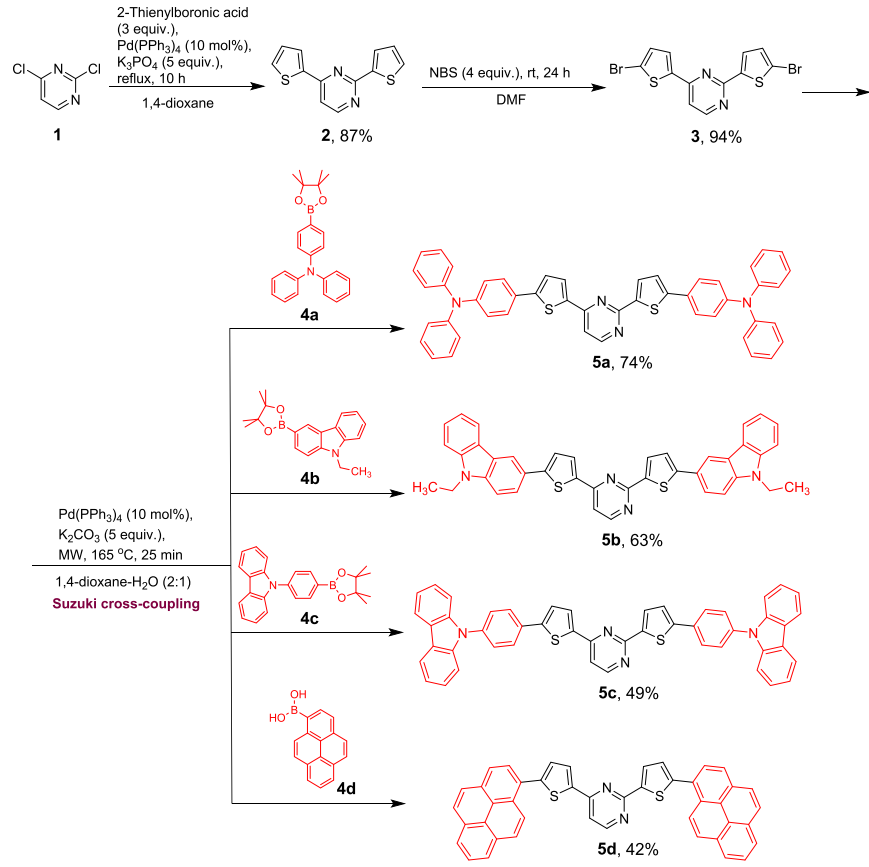

Scheme 1. Synthetic route to 2,4-bis[5-(heteroaryl)-thiophen-2-yl]pyrimidines (5a-d).

$41900 \mathrm{M}^{-1} \cdot \mathrm{cm}^{-1}$ ), respectively. UV-vis spectra for $\mathbf{5 a - d}$ in various solvents are shown in Figs. S2-S5.

It has been found that polarity of solvents exerts a weak influence on the long-wavelength absorption maxima of compounds 5a-d (Fig. 3). It can be attributed to a small change of the dipole moments of the molecules in the excited Franck-Condon state.

Effects of molecular structure on absorption properties are exhibited in bathochromic shifts of the long-wavelength absorption bands from carbazole $\mathbf{5 b}, \mathbf{c}$ to triphenylamine derivatives $\mathbf{5 a}$ (Table 1, Fig. 3). Since the ionization potential of triphenylamine is lower than that of carbazole, it might be supposed that enhancement of the electron-donative ability of the D-fragment of the dye causes a bathochromic shift. Such dependence is inherent for the absorption bands which are due to ICT [26].

In contrast to the absorption spectra, an increase in solvent polarity leads to bathochromic shifts of the emission maxima along with a successive decrease in the fluorescence intensity (Table 1, Figs. 4, S6-S9). The emission bands wavelengths exhibit a red shift with increasing of solvent polarity, and they cover a wide spectral range, providing solutions of various colors from blue to yellow-green one (Fig. S10). The change in the emission color can be seen easily by a naked eye, as shown in Fig. 4 for compounds 5a-d.

As an example, the spectra recorded for compound $\mathbf{5 a}$ are shown in
Table 1

Optical spectroscopy data 2,4-di(hetero)arylpyrimidines 5a-d.

\begin{tabular}{|c|c|c|c|c|c|}
\hline \multirow[t]{2}{*}{ Dye } & \multirow{2}{*}{$\begin{array}{l}\text { Solvent } \\
E_{\mathrm{T}}(30)^{\mathrm{a}} \\
(\mathrm{kcal} \\
\left.\mathrm{mol}^{-1}\right)\end{array}$} & \multirow{2}{*}{$\begin{array}{l}\text { Absorption } \lambda_{\max }(\mathrm{nm}) / \\
\varepsilon \\
\left(10^{3} \mathrm{M}^{-1} \mathrm{~cm}^{-1}\right)\end{array}$} & \multicolumn{2}{|c|}{ Photoluminescence } & \multirow{2}{*}{$\begin{array}{l}\text { Stokes shift } \\
-\Delta \nu_{\mathrm{St}}\left(\mathrm{cm}^{-1}\right)\end{array}$} \\
\hline & & & $\begin{array}{l}\text { Emission } \\
\lambda_{\max }(\mathrm{nm})\end{array}$ & $\Phi_{\mathrm{F}}^{\mathrm{b}}$ & \\
\hline $5 \mathbf{a}$ & Toluene & 404 (57.7), 303 (43.1) & 470 & 0.58 & 3476 \\
\hline $5 b$ & 33.9 & 389 (60.5), 290 (30.0) & 443 & 0.96 & 3134 \\
\hline $5 c$ & & 374 (60.2), $292(39.8)$ & 432 & 0.95 & 3590 \\
\hline $5 d$ & & 379 (54.3), 317 (29.0) & 461 & 0.18 & 4693 \\
\hline $5 \mathbf{a}$ & THF & 403 (54.7), 301 (41.0) & 504 & 0.45 & 4973 \\
\hline $5 b$ & 37.4 & 391 (56.4), 290 (28.3) & 464 & 0.67 & 4024 \\
\hline $5 c$ & & 371 (68.1), 291 (39.6) & 458 & 0.83 & 5120 \\
\hline $5 d$ & & $\begin{array}{l}377 \text { (61.8), } 316 \\
(30.4), 278(38.8)\end{array}$ & 471 & 0.15 & 5294 \\
\hline $5 \mathbf{a}$ & DCM & 406 (51.3), 302 (38.9) & 525 & 0.31 & 5583 \\
\hline $5 b$ & 40.7 & 392 (63.2), 289 (34.0) & 479 & 0.34 & 4633 \\
\hline $5 c$ & & 371 (65.2), $292(43.4)$ & 471 & 0.68 & 5723 \\
\hline $5 d$ & & $\begin{array}{l}379(60.5), 316 \\
(30.9), 278(41.9)\end{array}$ & 483 & 0.11 & 5681 \\
\hline $5 \mathbf{a}$ & Acetone & $401(67.6)$ & 531 & 0.16 & 6105 \\
\hline $5 b$ & 42.2 & $390(58.6)$ & 483 & 0.21 & 4937 \\
\hline $5 c$ & & $367(63.2)$ & 478 & 0.52 & 6327 \\
\hline $5 d$ & & $375(50.4)$ & 484 & 0.10 & 6006 \\
\hline $5 a$ & DMSO & 408 (62.7), $301(47.3)$ & 552 & 0.17 & 6394 \\
\hline $5 b$ & 45.1 & 398 (64.6), 290 (47.7) & 502 & 0.11 & 5205 \\
\hline $5 c$ & & 374 (68.5), 292 (47.7) & 502 & 0.40 & 6818 \\
\hline $5 d$ & & 383 (61.5), 318 (33.5) & 499 & 0.08 & 6070 \\
\hline
\end{tabular}

${ }^{\text {a }}$ Dimroth-Reichardt polarity parameter, $\mathrm{kcal} \mathrm{mol}^{-1}$ [25].

b Fluorescence quantum yield determined relative to quinine bisulfate in $0.1 \mathrm{M} \mathrm{H}_{2} \mathrm{SO}_{4}$ as standard $\left(\Phi_{\mathrm{F}}=0.52\right)$; excitation at $365 \mathrm{~nm}$ [24].

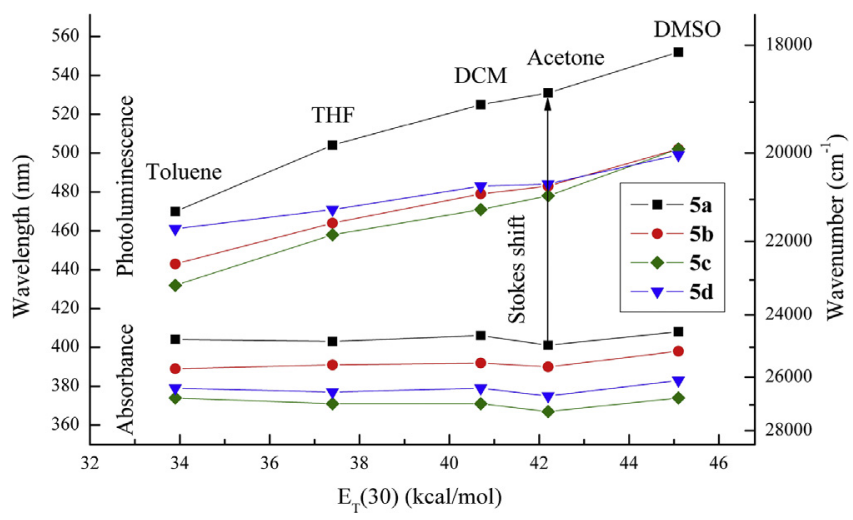

Fig. 3. Absorption and emission wavelength $\left(\lambda_{\max }\right)$ as a function of the Dimroth-Reichardt polarity parameter for dyes 5a-d.

Fig. S11, the emission wavelength maximum at $\lambda_{\mathrm{em}}=470 \mathrm{~nm}$ in the least polar solvent (toluene) is red-shifted by about $\Delta \lambda_{\text {em }}=82 \mathrm{~nm}$ $\left(\Delta \nu_{\mathrm{em}}=3161 \mathrm{~cm}^{-1}\right)$ on using DMSO as solvent $\left(\lambda_{\mathrm{em}}=552 \mathrm{~nm}\right)$. The

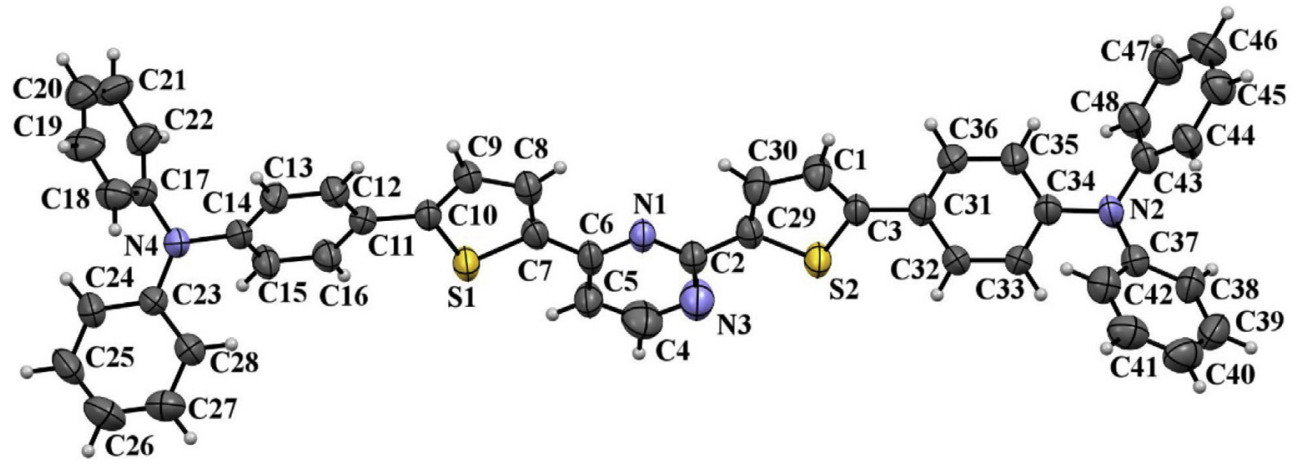

Fig. 2. ORTEP of 5a with thermal ellipsoids are at 50\% probability level. 


\section{Toluene THF DCM Acetone DMSO}

5a
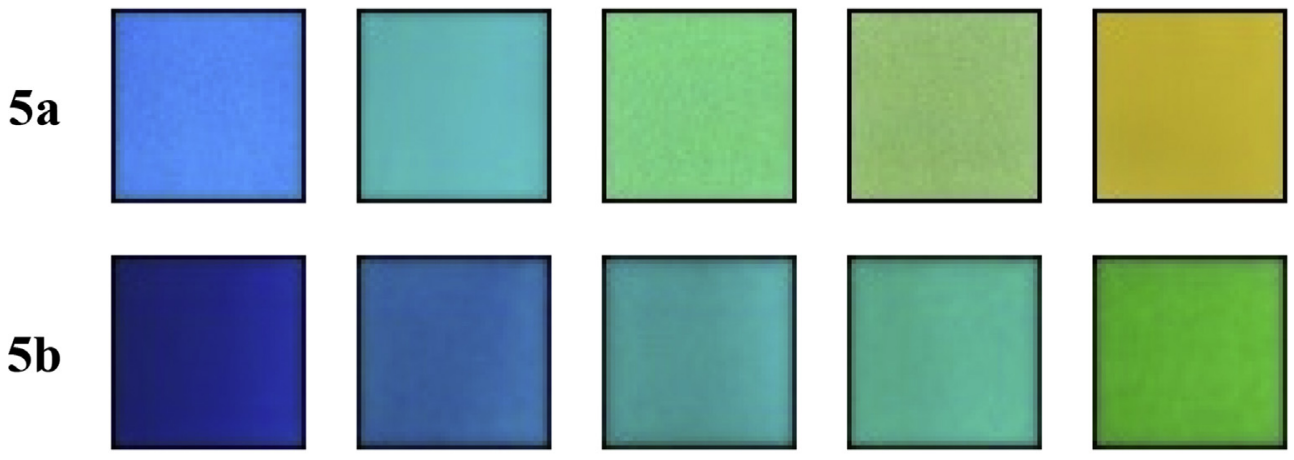

5c
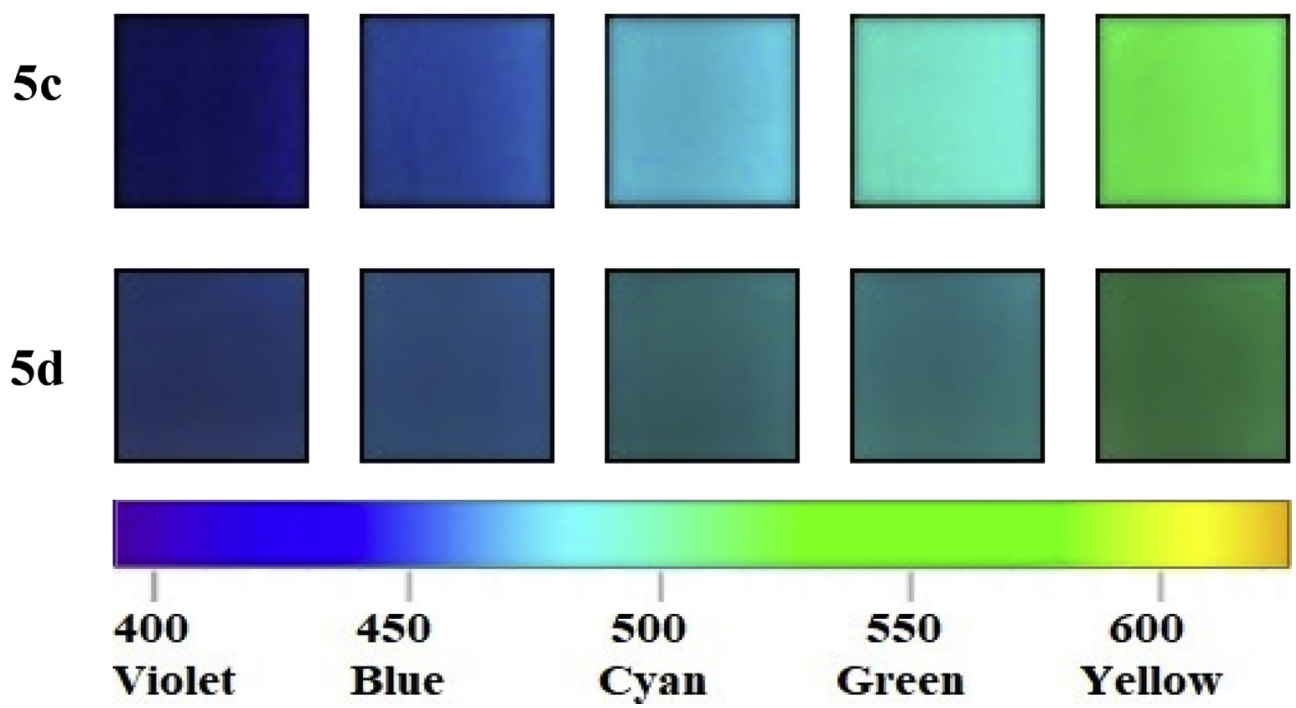

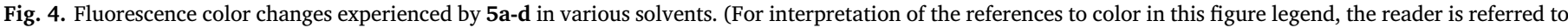
the Web version of this article.)

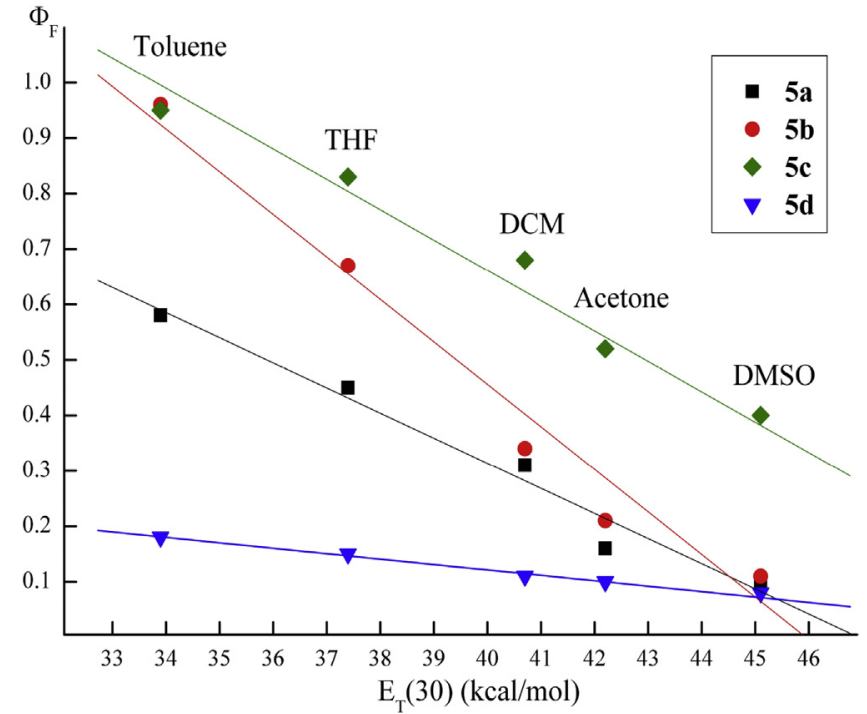

Fig. 5. Fluorescence quantum yield as a function of the Dimroth-Reichardt polarity parameter for dyes $\mathbf{5 a - d .}$

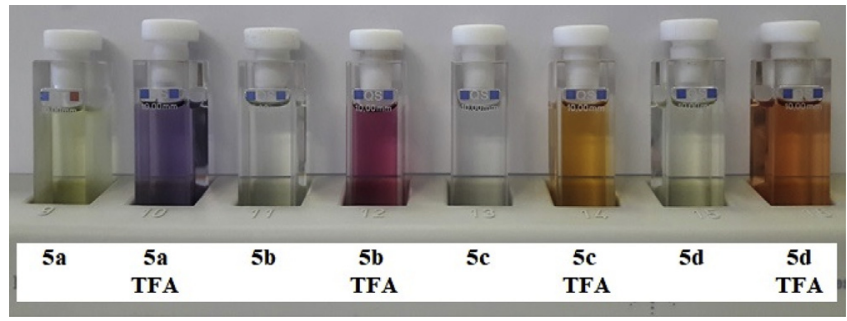

Fig. 6. Color change of DCM solutions of compounds 5a-d in the presence of TFA. (For interpretation of the references to color in this figure legend, the reader is referred to the Web version of this article.)

changes in the emission color for compounds $\mathbf{5 b}, \mathbf{5 c}$ and $\mathbf{5 d}$ are $59 \mathrm{~nm}$ $\left(\Delta \nu_{\mathrm{em}}=2653 \mathrm{~cm}^{-1}\right), \quad 70 \mathrm{~nm} \quad\left(\Delta \nu_{\mathrm{em}}=3228 \mathrm{~cm}^{-1}\right) \quad$ and $\quad 38 \mathrm{~nm}$ $\left(\Delta \nu_{\mathrm{em}}=1652 \mathrm{~cm}^{-1}\right)$, respectively. The excitation spectra of fluorescence are in good agreement with the absorption spectra for all dyes (Figs. S6-S9).

The observed correlation of the emission band wavelength with solvent-dependent $E_{\mathrm{T}}(30)$ Dimroth-Reichardt polarity parameter (see Fig. 3) is typical for compounds, which undergo the intramolecular photoinduced electron transfer, leading to a higher polarity state which stabilized by solvent $[9,25,27]$. 


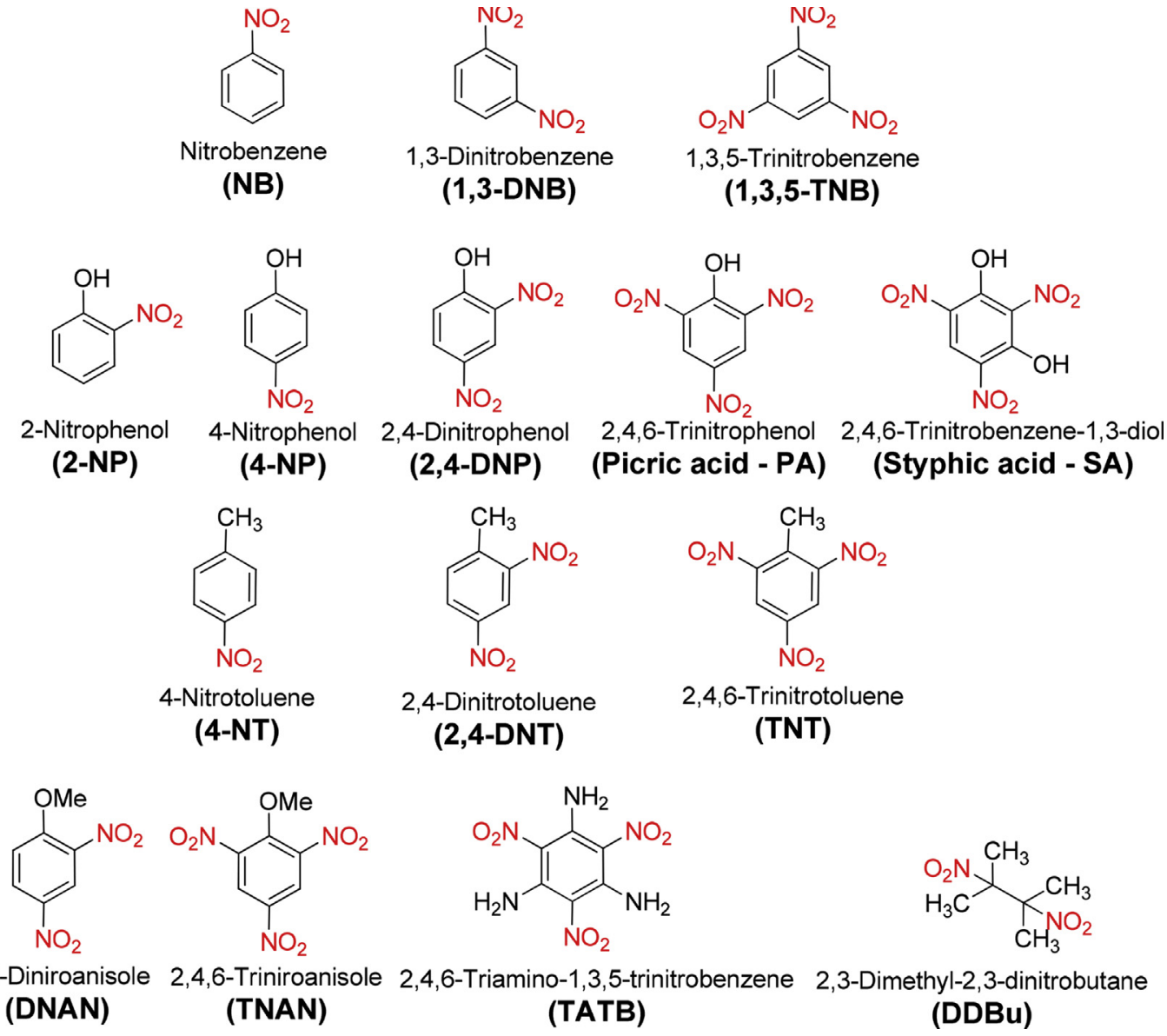

Fig. 7. Structures of used quenchers.

Table 2

Photophysical data for fluorophores 5a-d taken in acetonitrile.

\begin{tabular}{|c|c|c|c|c|c|}
\hline \multirow[t]{2}{*}{ Fluorophores } & \multirow{2}{*}{$\begin{array}{l}\text { Absorption } \\
\lambda_{\max }(\mathrm{nm}) / \varepsilon \\
\left(10^{3} / \mathrm{M}^{-1} \mathrm{~cm}^{-1}\right)\end{array}$} & \multicolumn{2}{|c|}{ Fluorescence } & \multirow{2}{*}{$\begin{array}{l}\text { Quantum } \\
\text { yield }(\Phi)\end{array}$} & \multirow{2}{*}{$\begin{array}{l}\text { Stokes shift } \\
\Delta \nu_{\mathrm{st}} / \mathrm{cm}^{-1}\end{array}$} \\
\hline & & $\begin{array}{l}\text { Excitation } \\
\lambda_{\max }(\mathrm{nm})\end{array}$ & $\begin{array}{l}\text { Emission } \\
\lambda_{\max }(\mathrm{nm})\end{array}$ & & \\
\hline $5 a$ & $401 / 99.00$ & 401 & 543 & 0.01 & 6521 \\
\hline $5 b$ & $389 / 89.00$ & 389 & 499 & 0.05 & 5667 \\
\hline $5 c$ & $369 / 37.00$ & 369 & 506 & 0.15 & 7337 \\
\hline $5 d$ & $370 / 36.00$ & 370 & 490 & 0.04 & 6619 \\
\hline
\end{tabular}

The Stokes shifts for 5a-d are increased with increasing of solvent polarity from 3134 to $4693 \mathrm{~cm}^{-1}$ in toluene to $5205-6818 \mathrm{~cm}^{-1}$ in DMSO (Table 1, Fig. 3 and S12). High values of Stokes shifts may be due to a remarkable change in dipole moment of dye molecules in the excited state, resulting from charge transfer from donor to acceptor fragment, which are accompanied by a compensatory relaxation of the solvent molecules [5,6,9,27].

The quantum yields for the fluorescence of the dyes $\mathbf{5 a - d}$ are strongly dependent on their molecular structures and polarity of solvents, thus varying from 0.08 to 0.96 (Table 1, Fig. 5).

With increase in polarity of the solvent, the quantum yields of the photoluminescence are reduced. Displacement of the carbazole fragment (compounds 5b, c) with triphenylamine (compounds 5a), having a stronger electron-donating character, also results in a decrease in quantum yields. Fluorescence quantum yields of 2,4-bis [5-(pyren-1-yl) thiophen-2-yl]pyrimidine $5 \mathrm{~d}\left(\Phi_{\mathrm{F}}=0.08-0.18\right)$ are much lower than those obtained for related compounds 5a-c $\left(\Phi_{\mathrm{F}}=0.11-0.96\right)$.

It has earlier been shown that 1,3-diazines can function as colorimetric and luminescent $\mathrm{pH}$ sensors, due to the basic character of their nitrogen atoms [9,11,27], which can be protonated. Protonation effects on photophysical properties of 5a-d dyes in dicloromethane solutions have also been studied. All compounds underwent a significant color change in the presence of TFA (Fig. 6). The changes in UV-vis absorption spectra of $\mathbf{5 a - d}$ upon addition of acid at different concentrations are presented on Figs. S13-S16.

Increasing concentration of TFA from $10^{-5}$ to $2 \times 10^{-2} \mathrm{M}$ leads to the progressive attenuation of the absorption band of the neutral compound and appearance of a new, red-shifted band, corresponding to protonated species, a change that was fully reversible by neutralization with base $\left(\mathrm{Et}_{3} \mathrm{~N}\right)$. This bathochromic shift of the absorption can be explained by an increased charge transfer from an electron-donative part to the pyrimidine moiety. As far as the fluorescence response of compounds 5a-d is concerned, the emission is totally quenched after protonation.

\subsection{Fluorescence sensory properties for probing nitroaromatics}

To evaluate an ability of fluorophores 5a-d to detect nitroaromatics and 2,3-dimethyl-2,3-dinitrobutane (DDBu), a common tag required by law for all commercial NATO plastic explosives, fluorescencequenching measurements in acetonitrile solutions containing measured quantities of different nitroaromatic compounds have been carried out using a well-known procedure [16-21] (Fig. 7). Their UV-vis absorption and emission spectra registered in MeCN are shown in Figs. S17a and S17b, respectively, and the data are presented in Table 2.

The fluorescence emission spectra of compounds $\mathbf{5 a - d}$ registered in the presence of various concentrations of analytes at the corresponding excitation wavelength are shown in Figs. S18-S21 (see Supporting Information). All nitroaromatics, as well as DDBu, appear to act as 
(a)

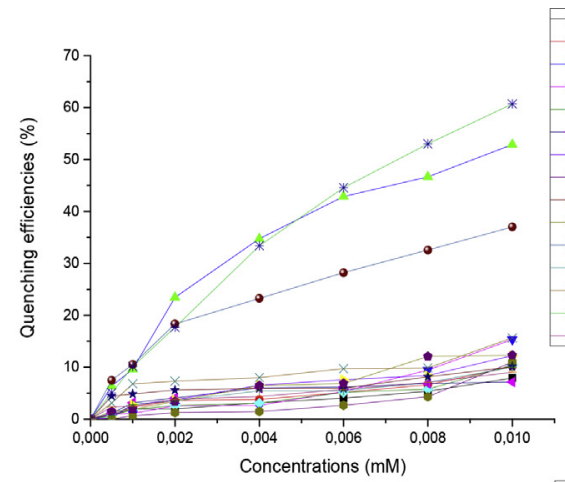

(c)

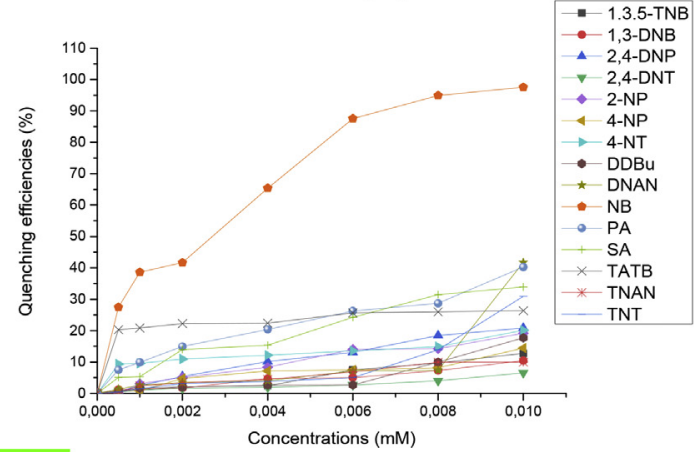

(b)

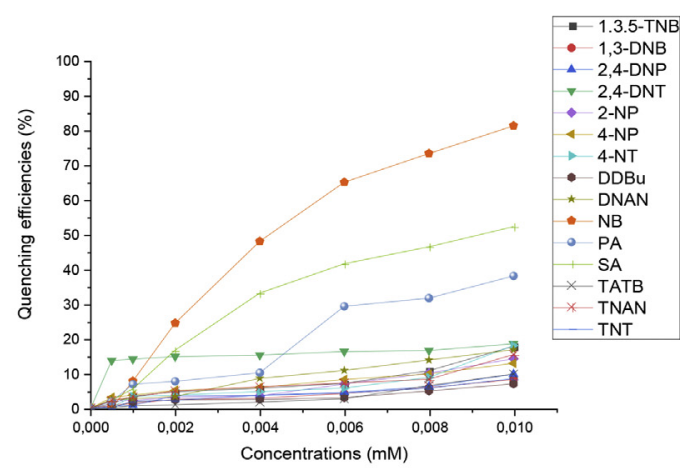

(d)

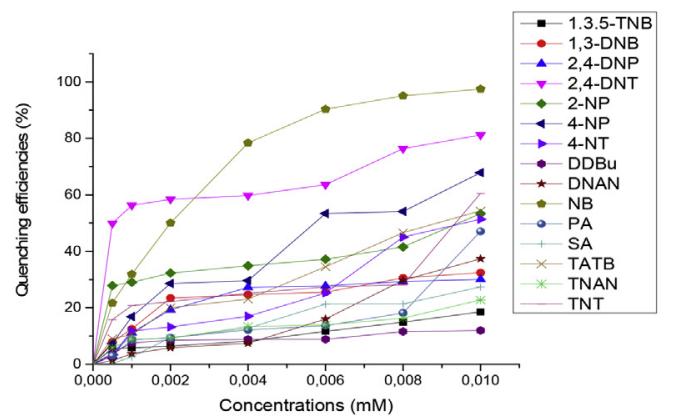

Fig. 8. The plot of quenching efficiencies of NB, 1,3-DNB, 1,3,5-TNB, 2-NP, 4-NP, 2,4-DNP, PA, SA, 4-NT, 2,4-DNT, TNT, DNAN, TNAN, TATB relative to fluorophores $\mathbf{5 a}(a), \mathbf{5 b}(b), \mathbf{5 c}(c)$ and $\mathbf{5 d}(d)$ at $\mathrm{mM}$ level in $\mathrm{CH}_{3} \mathrm{CN}$.

Table 3

Quenching constants $\left(K_{\mathrm{SV}}\right)$ and detection limits (DL) of NB, 1,3-DNB, 1,3,5-TNB, 2-NP, 4-NP, 2,4-DNP, PA, SA, 4-NT, 2,4-DNT, TNT, DNAN, TNAN, TATB and DDBu towards fluorophores $\mathbf{5 a - d}$ in $\mathrm{CH}_{3} \mathrm{CN}$.

\begin{tabular}{|c|c|c|c|c|}
\hline \multirow[t]{2}{*}{ Nitro-compound } & \multicolumn{4}{|c|}{ Ksv, $\mathrm{M}^{-1} / \mathrm{DL}, \mathrm{mol} \times \mathrm{L}^{-1}$} \\
\hline & Fluorophore 5a & Fluorophore $5 b$ & Fluorophore $5 c$ & Fluorophore $5 \mathrm{~d}$ \\
\hline NB & $853275 / 1.51 \times 10^{-6}$ & $438721 / 2.68 \times 10^{-6}$ & $3945186 / 1.20 \times 10^{-5}$ & $3844354 / 1.25 \times 10^{-5}$ \\
\hline 1,3-DNB & $103697 / 1.24 \times 10^{-5}$ & $9080 / 1.29 \times 10^{-3}$ & $11673 / 4.07 \times 10^{-3}$ & $48024 / 9.94 \times 10^{-4}$ \\
\hline $1,3,5-\mathrm{TNB}$ & $62556 / 2.06 \times 10^{-5}$ & $21691 / 5.42 \times 10^{-4}$ & $14606 / 3.25 \times 10^{-3}$ & $22738 / 2.11 \times 10^{-3}$ \\
\hline 2-NP & $53584 / 2.41 \times 10^{-5}$ & $16684 / 7.05 \times 10^{-4}$ & $23680 / 2.01 \times 10^{-3}$ & $114321 / 4.19 \times 10^{-4}$ \\
\hline 4-NP & $66208 / 1.95 \times 10^{-5}$ & $14844 / 7.92 \times 10^{-4}$ & $16891 / 2.81 \times 10^{-3}$ & $210807 / 2.27 \times 10^{-4}$ \\
\hline 2,4-DNP & $107184 / 1.20 \times 10^{-5}$ & $10882 / 1.08 \times 10^{-3}$ & $26319 / 1.81 \times 10^{-3}$ & $42973 / 1.12 \times 10^{-3}$ \\
\hline PA & $300380 / 4.29 \times 10^{-6}$ & $61618 / 1.91 \times 10^{-4}$ & $67436 / 7.05 \times 10^{-4}$ & $88909 / 5.39 \times 10^{-4}$ \\
\hline SA & $258484 / 4.99 \times 10^{-6}$ & $109703 / 1.07 \times 10^{-4}$ & $51338 / 9.25 \times 10^{-4}$ & $37731 / 1.27 \times 10^{-3}$ \\
\hline 4-NT & $64083 / 2.01 \times 10^{-5}$ & $22074 / 5.33 \times 10^{-4}$ & $25196 / 1.89 \times 10^{-3}$ & $105620 / 4.54 \times 10^{-4}$ \\
\hline 2,4-DNT & $62633 / 2.06 \times 10^{-5}$ & $22827 / 5.15 \times 10^{-4}$ & $7044 / 6.73 \times 10^{-3}$ & $431023 / 1.11 \times 10^{-4}$ \\
\hline TNT & $61522 / 2.10 \times 10^{-5}$ & $9329 / 1.26 \times 10^{-3}$ & $44743 / 1.06 \times 10^{-3}$ & $153016 / 3.13 \times 10^{-4}$ \\
\hline DNAN & $46067 / 2.80 \times 10^{-5}$ & $20259 / 5.80 \times 10^{-4}$ & $71618 / 6.63 \times 10^{-4}$ & $59598 / 8.04 \times 10^{-4}$ \\
\hline TNAN & $50968 / 2.53 \times 10^{-5}$ & $18357 / 6.41 \times 10^{-4}$ & $11049 / 4.03 \times 10^{-3}$ & $29461 / 1.63 \times 10^{-3}$ \\
\hline TATB & $49390 / 2.61 \times 10^{-5}$ & $10963 / 1.07 \times 10^{-6}$ & $35834 / 1.33 \times 10^{-3}$ & $118919 / 4.03 \times 10^{-4}$ \\
\hline DDBu & $41058 / 3.14 \times 10^{-5}$ & $7567 / 1.55 \times 10^{-3}$ & $21549 / 2.20 \times 10^{-3}$ & $13566 / 3.53 \times 10^{-3}$ \\
\hline
\end{tabular}

fluorescence quenchers for push-pull systems 5a-d. Visual changes of color for solutions of fluorophore $\mathbf{5 a}$ with additives of some nitroaromatic quenchers are shown in Fig. S22. It can be seen, that the greenish yellow color of the compound $5 \mathbf{a}$ has been changed after addition of PA, which can be detected easily by naked eyes. Other fluorophores $\mathbf{5 b}$-d behave in a similar manner towards the addition of PA and SA.

The quenching efficiency of a sensor can be described by the SternVolmer equation: $I_{O} / I=1+K_{\mathrm{SV}}[Q]$, herein, $I_{O}$ and $I$ are the fluorescence intensities in the absence and presence of a quencher, respectively, $K_{\mathrm{SV}}$ is the quenching constant and [Q] is the quencher concentration. Fig. 8 shows quenching efficiency of various nitroaromatics and DDBu towards fluorophores 5a-d. The calculated Stern-Volmer binding constants (Ksv) proved to have high values up to $3.8 \times 10^{6} \mathrm{M}^{-1}$ for fluorophores 5a-d towards different NACs (Table 3). Moreover, the detection limits for fluorophores 5a-d towards different NACs and DDBu were found to be in the range from $6.73 \times 10^{-3}$ to
$1.07 \times 10^{-6} \mathrm{~mol} / \mathrm{L}$. Surprisingly, the best quencher proved to be nitrobenzene. Nitrobenzene exhibits $60-96 \%$ quenching of 5a-d fluorescence at concentration $1.0 \times 10^{-5} \mathrm{~mol} / \mathrm{L}$. Apparently, the reason is the competition between solvent-analyte (solvation) and fluorophore-analyte interactions. The solvation energy for NB in acetonitrile is supposed to be much lower than that for other nitroaromatic compounds. Indirect confirmation of this hypothesis is that change of the solvent to a less polar dichloromethane leads to decrease in values of detection limits and the Stern-Volmer constants (see Supporting Information, Figs. S23 and S24, Table S1). In addition, the highest values of DL and Ksv were found for picric and styphnic acids, that was commonly observed for similar pyrimidine push-pull systems [16-21].

At low concentrations of NAC (from 0 to $1.0 \times 10^{-6} \mathrm{~mol} / \mathrm{L}$ ), linear Stern-Volmer plots were obtained, however, at high concentrations, the plots were found to be non-linear, showing positive curvature, as shown in Figs. S25-S28 (see Supporting Information). The nonlinearity suggests 


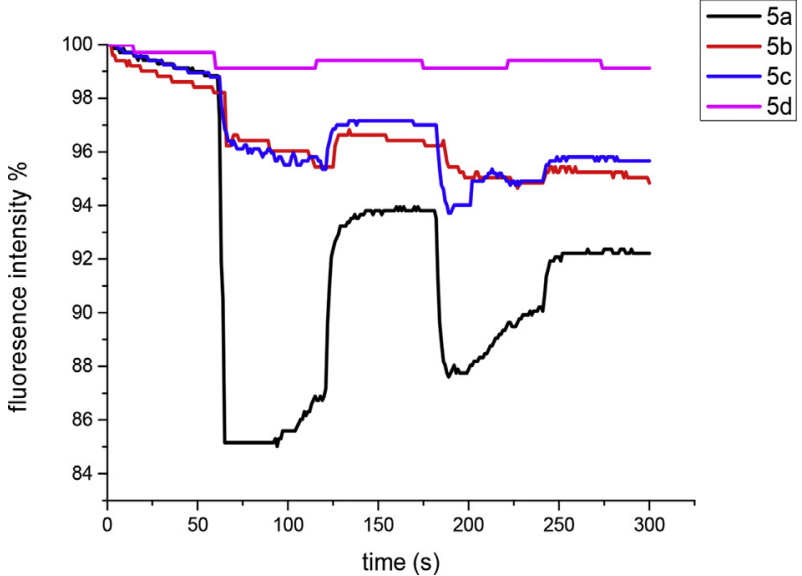

Fig. 9. Fluorescent recovery cycles for the sensors on the basis of compounds 5a-d in device « Zaslon-M » with exposure to saturated NB vapor.

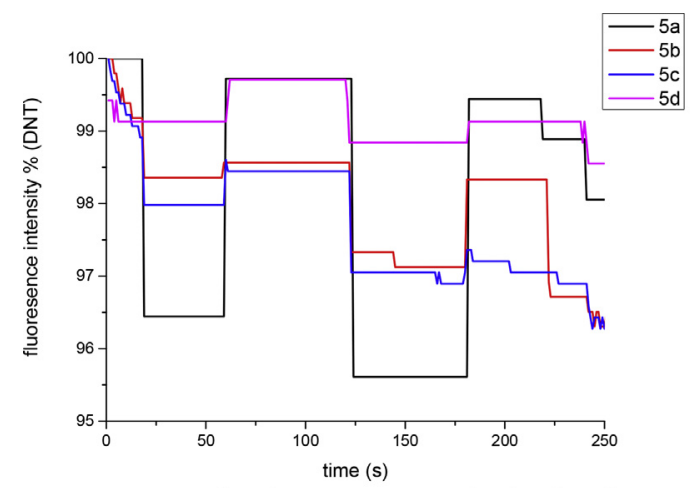

Fig. 10. Fluorescent recovery cycles for sensors on the basis of compounds 5a-d in device « Zaslon-M » with exposure to saturated DNT vapor.

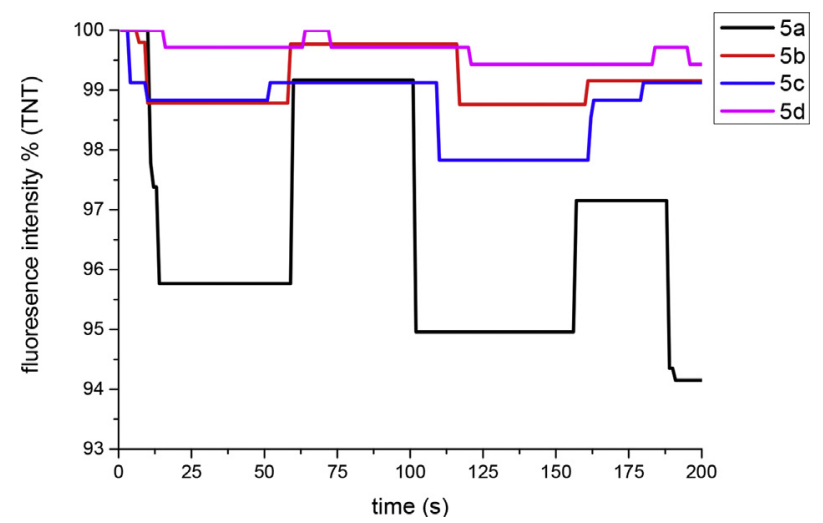

Fig. 11. Fluorescent recovery cycles for the sensors on the basis of compounds 5a-d in device « Zaslon-M » with exposure to saturated TNT vapor.

the mechanism of the quenching process, which can involve a combination of complexation and collisional processes.

Furthermore, to detect vapors of nitroaromatics is of importance for public safety. Many home-made explosive devices are fabricated by using impure TNT, in which the major impurity is 2,4-DNT, used as the starting material for the synthesis of TNT. Other precursors for TNT include 2,6-dinitrotoluene, para-nitrotoluene (4-NT) and nitrobenzene (NB), all of which are markers of the presence of explosive materials. Furthermore, dinitrotoluenes and nitrobenzene are known to be toxic, organic pollutants, which are frequently discharged into the

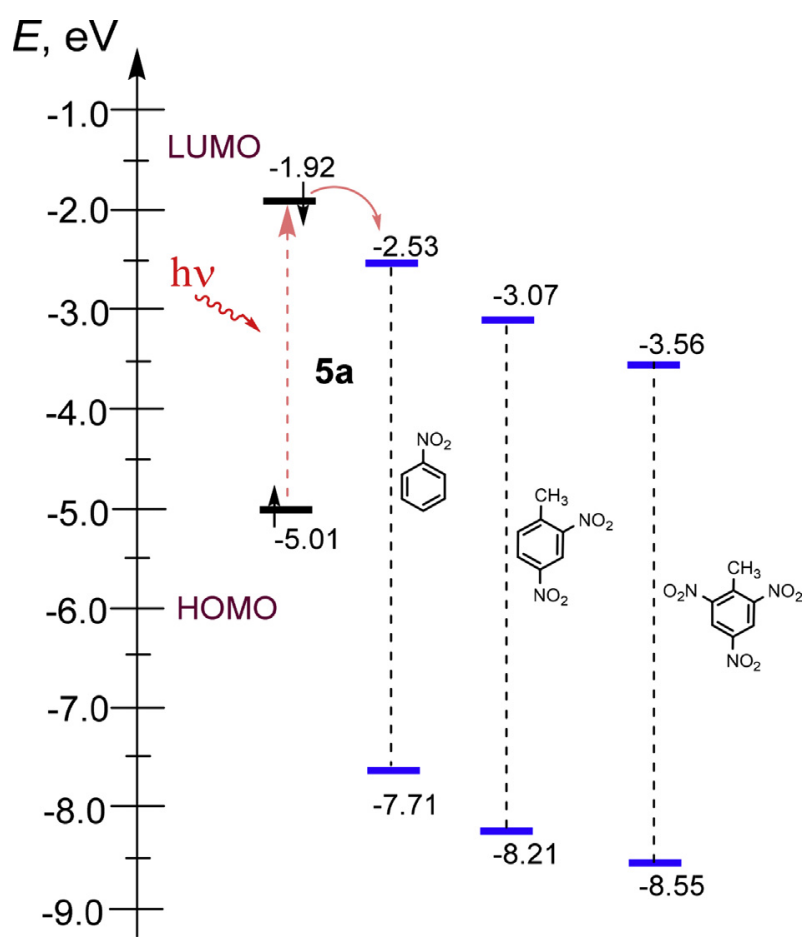

Fig. 12. Calculated energy level diagrams of compound $\mathbf{5 a}$ and the three nitroaromatic compounds tested.

environment by industrial production processes, and detection of these materials is of great importance [28].

We have prepared sensors with each of fluorophores $\mathbf{5 a - d ,}$, based on non-woven spunlace fabric placed in the portable sniffer «Zaslon-M», and investigated their fluorescence responses to saturated vapors of NB, DNT and TNT (see Experimental Part). As shown in Figs. 9-11, the emissions for fluorophores $\mathbf{5 a - d}$ in these sensors decreased significantly upon exposure to vapors of NACs. We have found that the quenching efficiency of fluorophores 5a-d towards NB was higher than that to DNT and TNT at the same temperature, because the vapor pressure of NB was much higher than that of DNT and TNT under such conditions. When the exposure time was maintained during the first cycle $(\sim 50 \mathrm{~s})$, the fluorescence quenching efficiency of the sensor based on $\mathbf{5 a}$ towards NB was $85.5 \%$, while the quenching efficiencies of compounds $5 \mathbf{b}-\mathbf{d}$ were $1-4 \%$. The situation proved to be similar with that in case of DNT and TNT. Therefore, the push-pull system $\mathbf{5 a}$ has exhibited a more sensitive response towards nitroaromatics than compounds $5 \mathbf{b}-\mathbf{d}$ (Figs. 9-11).

A more detailed insight into the fluorescence quenching mechanism of 5a-d on exposure to explosive vapors has been obtained by using $a b$ initio calculations. Geometry optimization and energy calculation for 5a-d and three nitroaromatic compounds were performed by using density-functional theory at the B3LYP/6-31G* level with the ORCA 4.0.3 program (Fig. 12, S29 and S30) [29].

The HOMO-LUMO gap of $\mathbf{5 a}$ is found to be smaller $(3.09 \mathrm{eV})$ than that of 5b-d (3.39, 3.22 and $3.19 \mathrm{eV}$, respectively), as shown in Fig. 12 and S30. LUMO of NB, DNT and TNT were found to be $-2.53,-3.07$ and $-3.56 \mathrm{eV}$, respectively. These data indicate that photo-induced electron transfer is possible between each of fluorophores $\mathbf{5 a - d}$ and quencher molecules, thus resulting in fluorescence quenching of the former. Fluorophores $\mathbf{5 a} \mathbf{a}, \mathbf{b}$ proved to exhibit a more sensitive response towards nitroaromatics, than compounds 5c,d (Figs. 9-11). The reason might be that the driving forces for the photo-induced electron transfer between $5 \mathrm{a}(0.61 \mathrm{eV}, 1.15 \mathrm{eV}$ and $1.64 \mathrm{eV}$ for NB, DNT and TNT) and 5b $(0.75 \mathrm{eV}, 1.29 \mathrm{eV}$ and $1.78 \mathrm{eV}$ for NB, DNT and TNT) quenchers proved to be lower than those between $5 \mathrm{c}(0.31 \mathrm{eV}, 1.15 \mathrm{eV}$ and $1.34 \mathrm{eV}$ for NB, DNT and TNT) and $5 \mathrm{~d}(0.39 \mathrm{eV}, 0.93 \mathrm{eV}$ and $1.42 \mathrm{eV}$ for NB, 


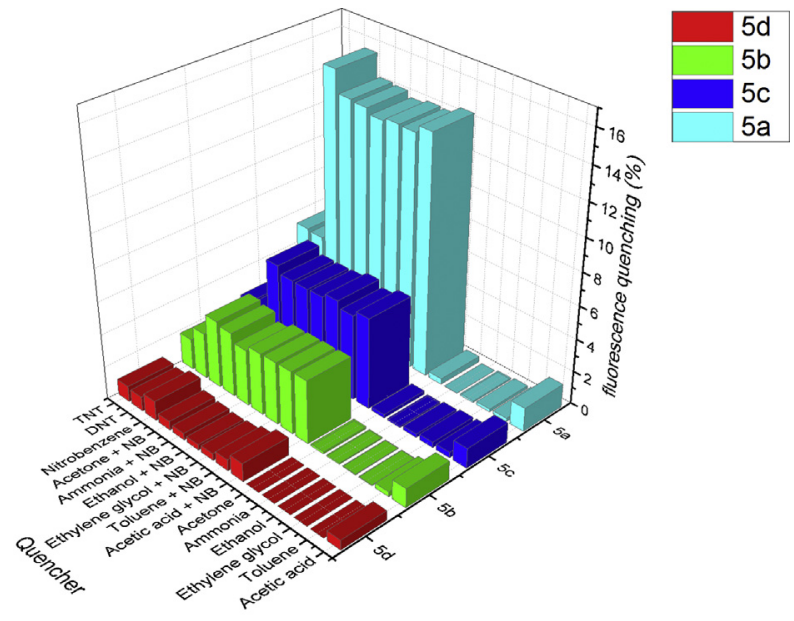

Fig. 13. Fluorescent quenching (\%) on the basis of compounds $\mathbf{5 a - d}$ in first cycle towards various nitro-explosives and volatile interferents at room temperature.

DNT and TNT) and the quenchers. Nonetheless, calculations cannot fully explain all experimental findings, since contribution of other factors.

To evaluate the selectivity of the sensors $\mathbf{5 a - d}$, the fluorescence response towards other quenchers' vapors have been performed. Indeed, sensor 5a shows a good selectivity to NB in comparison with other NACs (DNT and TNT) and interferents, such as ammonia, ethanol, ethylene glycol, acetone, acetic acid and toluene (see Fig. 13), since their quenching sensitivities are weaker in these vapors that in NB. It is worth noting, that concentration of vapor for interferent liquids is several times higher than that for solid NACs (see Experimental part). Deviation of the fluorescence quenching in the presence of NB from these interferents was less than $1.5 \%$. The results obtained demonstrate that the NB detection has no significant influence from selected interferents.

\section{Conclusion}

The series of new V-shaped 2,4-di(hetero)arylpyrimidine push-pull systems have been synthesized and studied, as a sensing fluorophores. The $\mathrm{pH}$-sensing properties of these compounds display a dramatic and reversible color change switching upon addition of an acid, as result of protonation of nitrogen atoms of the pyrimidine ring. These findings suggest that spectroscopic properties of the D- $\pi-A-\pi-D$ type pyrimidine dyes enable promising colorimetric $\mathrm{pH}$ sensors to be developed. Furthermore, the compounds obtained can be regarded as suitable sensing materials for the hand-held sniffer "Zaslon-M», since they exhibit a good potential and pretend to be fast-response, highly sensitive and selective sensors for NB in vapors.

\section{Acknowledgments}

This work (synthetic part and sensory properties) was supported by the Russian Foundation for Basic Research (Research Project No. 17-0300011-A). N.I. Makarova, E.V.V. and A.V.M. would like to acknowledge financial support for the absorption and fluorescence studies from the Ministry of Education and Science of the Russian Federation within the framework of the State Assignment for Research (project No. 4.6759.2017/BC). The authors are grateful to Mr. Grigory A. Kim for carrying out the DFT calculations which were performed by using «Uran» supercomputer of the Institute of mathematic and mechanics of the Ural Brach of the Russian Academy of Sciences. NMR experiments were carried out by using equipment of the Center for Joint Use "Spectroscopy and Analysis of Organic Compounds" at the
Postovsky Institute of Organic Synthesis of the Ural Branch of the Russian Academy of Sciences. VNC is grateful to the Ural Branch of the Russian Academy of Sciences (project № 0398-2018-0054).

\section{Appendix A. Supplementary data}

Supplementary data related to this article can be found at http://dx. doi.org/10.1016/j.dyepig.2018.05.075.

\section{References}

[1] Achelle S, Rodríguez-López J, Robin-le Guen F. Photoluminescence properties of aryl-, arylvinyl-, and arylethynylpyrimidine derivatives. Chemistry 2018;3:1852-86.

[2] Weng J, Mei Q, Ling Q, Fan Q, Huang W. Tetrahedron 2012;68:3129-34.

[3] Hadad C, Achelle S, López-Solera I, García-Martínez JC, Rodríguez-López J. Metal cation complexation studies of 4-arylvinyl-2,6-di(pyridin-2-yl)pyrimidines: effect on the optical properties. Dyes Pigments 2013;97:230-7.

[4] Mati SS, Chall S, Konar S, Rakchit S, Bhattacharya SC. Pyrimidine-based fluorescent zinc sensor: photo-physical characteristics, quantum chemical interpretation and application in real samples. Sens Actuators, B 2014;201:204-12.

[5] Verbitskiy EV, Cheprakova EM, Subbotina JO, Schepochkin AV, Slepukhin PA Rusinov GL, Charushin VN, Chupakhin ON, Makarova NI, Metelitsa AV, Minkin VI. Synthesis, spectral and electrochemical properties of pyrimidine-containing dyes as photosensitizers for dye-sensitized solar cells. Dyes Pigments 2014;100:201-14.

[6] Verbitskiy EV, Schepochkin AV, Makarova NI, Dorogan IV, Metelitsa AV, Minkin VI, Kozyukhin SA, Emets VV, Grindberg VA, Chupakhin ON, Rusinov GL, Charushin VN. Synthesis, photophysical and redox properties of the D- $\pi-A$ type pyrimidine dyes bearing the 9-phenyl-9H-carbazole moiety. J Fluoresc 2015;25:763-75.

[7] Achelle S, Barsella A, Caro B, Robin-le Guen F. Donor-linker-acceptor (D- $\pi-A$ ) diazine chromophores with extended $\pi$-conjugated cores: synthesis, photophysical and second order nonlinear optical properties. RSC Adv 2015;5:39218-27.

[8] Cvejn D, Achelle S, Pytela O, Malval JP, Spangenberg A, Cabon N, Bureš F, Robin-le Guen F. Tripodal molecules with triphenylamine core, diazine peripheral groups and extended p-conjugated linkers. Dyes Pigments 2016;124:101-9.

[9] Achelle S, Nouira I, Pfaffinger B, Ramondenc Y, Plé N, Rodríguez-López J. V-shaped 4,6-Bis(arylvinyl)pyrimidine oligomers: synthesis and optical properties. J Org Chem 2009;74:3711-7.

[10] Achelle S, Barsella A, Baudequin C, Caro B, Robin-le Guen F. Synthesis and photophysical investigation of a series of push-pull arylvinyldiazine chromophores. J. Org Chem 2012;77:4087-96.

[11] Achelle S, Rodríguez-López J, Robin-le Guen F. Synthesis and photophysical studies of a series of quinazoline chromophores. J Org Chem 2014;79:7564-71.

[12] Tang R, Wang X, Zhang W, Zhuang X, Bi S, Zhang W, Zhang F. Aromatic azaheterocycle-cored luminogens with tunable physical properties via nitrogen atoms for sensing strong acids. J Mater Chem C 2016;4:7640-8.

[13] Boländer A, Kiesser D, Voss C, Bauer S, Schçn C, Burgold S, Bittner T, Hçlzer J, Heyny-von Haußen R, Mall G, Goetschy V, Czech C, Knust H, Berger R, Herms J, Hilger I, Schmidt B. Bis(arylvinyl)pyrazines, -pyrimidines, and -pyridazines as imaging agents for Tau fibrils and $\beta$-amyloid plaques in Alzheimer's disease models. J Med Chem 2012;55:9170-80.

[14] Aranda AI, Achelle S, Hammerer F, Mahuteau-Betzer F, Teulade-Fichou MP. Vinyldiazine triphenylamines and their $\mathrm{N}$-methylated derivatives: synthesis, photophysical properties and application for staining DNA. Dyes Pigments 2012;95:400-7.

[15] Verbitskiy EV, Rusinov GL, Chupakhin ON, Charushin VN. Recent advances in Direct C-H functionalization of pyrimidines. Synthesis 2018;50:193-210.

[16] Verbitskiy EV, Baranova AA, Lugovik KI, Shafikov MZ, Khokhlov KO, Cheprakova EM, Rusinov GL, Chupakhin ON, Charushin VN. Detection of nitroaromatic explosives by new D- $\pi-\mathrm{A}$ sensing fluorophores on the basis of the pyrimidine scaffold. Anal Bioanal Chem 2016;408:4093-101.

[17] Verbitskiy EV, Baranova AA, Lugovik KI, Khokhlov KO, Cheprakova EM, Rusinov GL, Chupakhin ON, Charushin VN. New V-shaped push-pull systems based on 4,5-di (hetero)aryl substituted pyrimidines: their synthesis and application to the detection of nitroaromatic explosives. ARKIVOC 2016;iii:360-73.

[18] Verbitskiy EV, Cheprakova EM, Baranova AA, Khokhlov KO, Lugovik KI, Rusinov GL, Chupakhin ON, Charushin VN. Microwave-assisted synthesis of 4-(2,2'-bithiophen-5-yl)-5-phenylpyrimidine derivatives as sensors for detection of nitroaromatic explosives. Chem Heterocycl Comp 2016;52:904-9.

[19] Verbitskiy EV, Baranova AA, Lugovik KI, Khokhlov KO, Cheprakova EM, Shafikov MZ, Rusinov GL, Chupakhin ON, Charushin VN. New 4,5-di(hetero)arylpyrimidines as sensing elements for detection of nitroaromatic explosives in vapor phase. Dyes Pigments 2017;137:360-71.

[20] Verbitskiy EV, Baranova AA, Yakovleva YA, Chuvashov RD, Khokhlov KO, Dinastiya EM, Rusinov GL, Chupakhin ON, Charushin VN. New "turn-off" fluorescence sensors to detect vapors of nitro-explosives on the basis of 4,6-bis[5-(heteroaryl)thiophen-2-yl] substituted 5-(4-tert-butylphenyl)pyrimidines. ARKIVOC 2017;341-355.

[21] Verbitskiy EV, Baranova AA, Lugovik KI, Khokhlov KO, Chuvashov RD, Dinastiya EM, Rusinov GL, Chupakhin ON, Charushin VN. Linear and V-shaped push-pull systems on a base of pyrimidine scaffold with a pyrene-donative fragment for detection of nitroaromatic compounds. J Iran Chem Soc 2018;15:787-97. 
[22] Monthéard JP, Dubois JC. Préparation de dithiényl-2-éthène-1,2, de dithiényl-2pyrimidine-2,4 et de dithiényl-2-pyridazine-3,6. J Heterocycl Chem 1985;22:719-20.

[23] Farahat AA, Boykin DW. Unusual regioselective reactions of 2,4-bis(methylsulfanyl) pyrimidine under modified Suzuki and Stille cross-coupling conditions. Synthesis 2012;44:120-4.

[24] Meech SR, Phillips D. Photophysics of some common fluorescence standards. J Photochem 1983;23:193-217.

[25] Reichardt C, Welton T. Solvents and solvent effects in organic chemistry. Weinheim: WILTY-VCH Verlag GmbH \& Co. KGaA; 2011.
[26] Barltrop JA, Coyle JD. Excited states in organic chemistry. London. New York: Wiley; 1975. p. 376.

[27] Hadad C, Achelle S, Garcia-Martinez JC, Rodriguez-Lopez J. 4-Arylvinyl-2,6-di (pyridine-2-yl)pyrimidines: synthesis and Optical Properties. J Org Chem 2011;76:3837-45.

[28] Beauchamp RO, Irons RD, Rickert DE, Couch DB, Hamm TE. A critical review of the literature on nitrobenzene Toxicity/CRC crit. Rev Toxicol 1982;11:33-84.

[29] Neese F. The ORCA program system. Wiley Interdiscip Rev. Comput. Mol. Sci. 2012;2:73-8. 